\title{
Choroidal and Ciliary Body Melanoma by AJCC v8 Stage
}

National Cancer Institute

\section{Source}

National Cancer Institute. Choroidal and Ciliary Body Melanoma by A/CC v8 Stage. NCI Thesaurus. Code C140659.

A term that refers to the staging of choroidal and ciliary body melanoma, following the rules of the TNM AJCC V8 classification system. 